\title{
EL DOCUMEN'TO RATZINGER: REFLEXIONES PARA CREYENTES EN TORNO A UN PROBLEMA
}

Por Antonio MARZAL

El título, algo complicado, quiere distinguir dos cosas: el documento y el problema. O, si se quiere, el problema Ratzinger y el problema problema. ¿Un problema adjetivo, y otro sustantivo? Quizá no me parecería malo ese modo de aproximación al tema. Pero a condición de que el tratamiento de ese, o esos problemas, no sea luego meramente formal, sino que los hagamos entrar en las múltiples conexiones e interdependencias con que históricamente vivimos y hemos vivido ese tipo de problema. Lo que yo propongo, pues - y éste es el sentido de mi contribución a este debate-, es una aproximación histórica a uno y otro problema. Porque estoy convencido de que sólo desde esta conciencia histórica - desde la conciencia de nuestra propia historia de creyentes de los últimos veinte o veinticinco años-se ilumina el sentido último y hasta la pasión de este debate.

\section{La doctrina social de la Iglesia antes y después de Juan XXIII}

Es difícil no mirar con suspicacia el documento Ratzinger. Por más nombre propio que tenga, es, a fin de cuentas - nos costaría en todo caso, no ver en él-, un documento autoritativo romano. Y Roma, ya se sabe, tiene entre nosotros, los creyentes, una vieja, larga y excesiva tradición de autoritarismo/autoridad. Y, lo que es aún más grave, de sensibilidad anti, de percepción condenatoria de los problemas. El conjunto de la doctrina social pontificia, es, para mí, ante todo eșo, y sin que por ello desconozca los lados positivos de aquélla. Frente a Calvez, en su inteligente obra "Eglise et société économique", yo he defendido en otro sitio (1) el carácter esencialmente anti del conjunto de ese cuerpo sistemático de doctrina moral económica que es, en esencia, la doctrina social de la Iglesia, y que, por ello, sólo en una lec-

(1) Antonio Marzal, Empresa y Democtacia Econónica, Atgot, Barcelona, 1983, págs. $81-82$ 
tura de su reverso, es percibible como una doctrina pro, una doctrina en sí, si se me permite este germanismo algo pretencioso. La interpretación contraria de Calvez me parece inteligente, pero más prospectiva que interpretativa, más wishfull thinking que descripción de lo que es o ha sido.

Este úl timo "ha sido" es también intencionado. Porque la doctrina social pontificia (en la que querría inscribirse, aunque sea en tono muy menor, el documento Ratzinger) es, a mi juicio, un corpus de doctrina histórico, $y$, en este sentido, ya muerto. Murio, me parece, con Juan XXIII. Murió heroicamente, hegelianamente, en una especie de superación de sí misma, cuando el élan moral o ético, que subyacía en ella desde su nacimiento, llegó a un grado de expresión tal, que la hizo incompatible con su otra expresión de corpus de doctrina con un contenido ideológico, global, sistemático y concreto. Después de Juan XXIII ha habido, por supuesto, Encíclicas Sociales. Ahí está Paulo VI. Y ahí está también Juan Pablo II, con la Laborem Exercens. $Y$ hasta me atrevería a sugerir que seguramente $-y$ por razones no dificilmente percibibles, que algo tendrán que ver con los inconscientes o los implícitos salidos de la experiencia-, no existe una Encíclica Social de contenido tan moderno como la Laborem Exercens. Probablemente en ninguna otra Encíclica Social se había dado tan acusadamente como en ésta, la relativización de todo sistema socioeconómico. $Y$, consiguientemente, es posible que en ninguna otra Enciclica Social quede tan claramente afirmado, como en ésta, desde una perspectiva estrictamente analítica, que el sitio de la moral, que el topos de la utopía cristiana ética, sólo puede identificarse en la ineludible y permanente tensión inestable entre el sistema y el sujeto, a cuyo servicio se construye teóricamente todo sistema.

Pero todo ello no invalida la afirmación de que parto. Lo que viene después de Juan XXIII habría que llamarlo no doctrina, sino posdoctrina (social pontificia), si se me permite la utilización hoy tan de moda, de este pos expresivo. La Laborem Exercens, aún pensada tan positivamente como yo sugiero, s6lo sería posdoctrina social pontificia. Simple pensamiento - uno más- socialcristiano. La doctrina social pontifica como cuerpo sistemático de doctrina autoritativa (o autotitaria) de los Pontifícies, o de la Iglesia, ya había muerto. Murió con Juan XXIII, porque justamente lo que murió con Juan XXIII es esa concepción autoritativa/autoritaria del pensamiento de la Iglesia.

\section{El complejo "anti Roma"}

En todo caso así lo hemos percibido y vivido la generación de creyentes a que aludía, cuando he propuesto un análisis histórico (de los últimos $20 \circ 25$ años) del problema. Lo que el Concilio y Juan XXIII significaron en los años sesenta, fue ese cambio de cultura eclesiástica (que por eso comenzamos a llamar eclesial), en la que el pensamiento, la intelligentia fidei, dejaban de venir dadas desde arriba, autoritativamente. El Papa no era demasiado importante, nos dijimos. Y con razón, creo. Peto una vez descubierto eso, que es lo mismo que descu- 
brir, por imperativos de la propia fe, la libertad de pensar de la Iglesia, lo que quizá haya pasado es que no hemos sabido qué hacer luego con aquélla. A la Iglesia moderna se le podía aplicar análogamente la crí tica que Marx hizo al capitalismo. Que había creado decía Marzmás riqueza que todas las otras generaciones juntas, pero luego, una vez creada, no sabía qué hacer con ella. En la Iglesia de hoy, con la libertad, está sucediendo algo semejante. Y después de haber afirmado que el Papa no es importante, terminamos haciéndole de nuevo importante, para poder seguir jugando a la contra, nostálgicamente reinstalados en el sentido heroico, y por hetoico atrayente, de ese juego. Una buena parte de las suspicacias ante el documento Ratzinger tienen aquí su explicación, o aquí echan, en todo caso, sus raíces. Una buena parte del tono condenatorio que vemos en el documento, quizá esté, más que en el documento, en nosotros que lo leemos. X en el límite, estaramos afirmando - sin quererlo- que en la actual Iglesia todos tenemos derecho a la libertad de pensar, menos... Roma. La Roma oficial o la Roma oficiosa, todo lo que huela a Roma. La Roma que sigue siendo tan importante, para que nosotros nos sintamos obligados a decirla que se calle. Incluso si simplemente razona o piensa. $O$ si razona y piensa - decimos- con una pretendida autoridad que no tiene, y que molesta, pero que, al mismo tiempo, una buena parte de los creyentes hemos evacuado radical y sinceramente hace ya mucho tiempo. Sé que todo esto se presta a polémicas razonables y a matices que siguen teniendo sentido. Pero por encima de todo eso, me sigue pareciendo que el hecho fundamental es el que aquí apunto. Sin esta tortuosa historia nuestra, el documento Ratzinger suscitaria bastantes menos suspicacias de las que los medios de comunicación y los círculos enterados han puesto en movimiento. El complejo "anti Roma" es una parte residual del complejo "Roma", que nos atenazó y nos bloqué en su tiempo. Y sin acabar con ese complejo, no me parece históricamente posible éncontrar una salida al problema o a los problemas del actual debate en el que tomo yo parte aquí personalmente. Como dirían los Mitscherlich, no hemos matado definitivamente al padre - que resucita en cada momento- porque no hemos consumado el duelo.

\section{De la conciencia moral a la conciencia política}

Este mismo proceso genérico, que he apuntado en el apartado anterior, ha provocado en nosotros, historicamente, otros dos efectos menores, cuyo análisis considero también previo al debate en sí de la teologia - o, como dice el documento Ratzinger, de las teologías - de la liberación.

1. Un primer efecto - repito que de tono menor y que quisiera apuntar ahota- podría expresarse de la siguiente manera. En una concepción autoritaria, como la de la Iglesia de la que venímos los de la generación de creyentes de los afios sesenta, lo que estaba prohibido configuraba por su teverso positivo nuestro comportamiento. El comportamiento (positivo) adquitía su forma en el molde (negativo) 


\section{ANTONIO MARZAL}

de la prohibición. El cristiano no podía ser marxista - se decía- por esenciales incompatibilidades con la fe. Como, en teoría, tampoco podía profesar el liberalismo económico, por incompatibilidades con la teoría moral católica. El invento de un sistema económico "católico", y hasta de un ideal de "empresa católica", no era más que el reverso de aquel anverso, como ya sugería más arriba. Pero ahora lo que me interesa subrayar, es que ese paradigma de comportamiento (prohibición negativa en el anverso/imagen positiva en el reverso), que venía vinculado por la tradición autoritaria de esa doctrina, se vino abajo lógicamente con la muerte del autoritarismo, té́rico y práctico, de la Iglesia. Lo que quizá no murió con él, es un cierto infantilismo agazapado en él. Ylo que ha podido suceder entonces es que, al percibirse como caída la prohibición, se ha llegado a percibir como deber lo antes prohibido. Del "no se puede ser marxista y cristiano", se pasó, no al "se puede ser marxista y cristiano" (conclusión puramente lógica), sino al "es preciso ser marxista para ser cristiano", conclusión que sólo es lógica si se introducen además otros elementos. Sin duda, esos elementos se introdujeron más o menos conscientemente. Peto todos ellos me parecen más elementos psicológicos (que explican una lógica percibida), que lógicos (que sustenten una lógica real y contrastada). Estaba por ejemplo la experiencia política de las democracias cristianas, o la sindical de los sindicatos cristianos (a un paso apenas de los movimientos obreros católicos de apostolado) que justificaban el bandazo hacia el otro lado. Pero estaba sobre todo el mecanismo psicológico infantil, que pasa de la prohibición "al deber ser" o al "vale la pena ser", sin solución de continuidad, en una aparente lógica infantil del blanco y el negro, del sí o del no, de los extremos. Si somos sinceros, hay mucho de eso en nuestra propia experiencia generacional. $Y$ mucho de las teologías de la liberación echan sus oscuras raíces psicológicas en eso, en la ruptura del tabú y de la prohibición que se convierten, sin solución de continuidad, en mitos paradisiacos.

2. El otro efecto - también menor-que apunté en este apartado, tiene ciertas similaridades y conexiones con el primer efecto. La conciencia cristiana en torno a los grandes temas económicos había sido conciencia moral. No podía ser de otro modo, en rigor. Quizá tampoco dejó de serlo, porque inconscientemente se quiso eludir la conciencia concreta. La moral parece suponer siempre un cierto grado de abstracción, que el conservadurismo católico ha sabido utilizar ampliamente. Esa motal sólo era concreta en las prohibiciones.

Pero, la tuptura con ese esquema moral de la prohibición quiso también recuperar lo concreto para el comportamiento positivo, y con la recuperación de lo concreto descubrió - tenía que descubrirlo político. Y la tradición hegeliana del marxismo se convirtió con naturalidad en el campo de expresión privilegiado de ese cambio, en su superación hegeliana, su Aulhebung. La moral cristiana era llevada al fin, al estadio superior de lo político. De lo político como expresión suprema de lo moral. Los años sesenta, ákme político expresivo de la cultura salida de la $2 .^{2}$ guerra, ayudaron sin duda a ese cambio de la 
conciencia cristiana, de conciencia moral a conciencia política. Eran los años que desde el punto de vista de la historiografía marxista, Bartoli (un católico de izquierda, un católico marxista quizá) llamó "los años de la obsesión" (frente a los "años de la ignorancia", hasta la comuna del 71, y "los años del descubrimiento", hasta la 2." Guerra Mundial) (2). Las teologías de entonces echaron aquí también sus raíces sin duda. Teologías de la esperanza o de la liberación. Teologías políticas, se llamaron, para ponerse a tono con los tiempos.

En realidad teologías políticas de izquierda, si se quería que el descubrimiento fuera original. Porque teologías políticas de derecha las había habido. Y muchas, antes. Más recientes (un Carl Smitt, creador del término en Alemania, y bien asimilado luego por el nazismo, o los Nocedal, y los Vázquez de Mella entre nosotros) o más antiguas (desde Tomás de Aquino con su Summa hasta Agustín y su Ciudad de Dios). De ahíla necesidad psicológica de olvidar ciertos pasados y de afirmar, desde la izquierda, la esencia política de la teología, como un nuevo y original descubrimiento, frente al moralismo vacío y abstracto, inútil por abstracto, de la teología clásica. Era el dominio de la conciencia política, de la conciencia al fin adulta, en el panorama, alienante por apolítico, de la teología cristiana. Eta la afirmación de lo político como superior a lo moral, o de lo político como expresión suprema de lo moral. Algo que, era posible leer directamente, sin necesidad de traducción, en la vieja tradición veterotestamentatia de los profetas. De ahí su vuelta a ellos. Y su vuelta a ellos como a una Edad de Oro que sirviese de punto concreto de referencia.

\section{Las TL en una perspectiva analítica: puntos débiles a la crítica}

Para ello, se olvidaba que una lectura así tenía sus inconvenientes. La lectura sionista agnóstica había utilizado esa teología política profética, en apoyo de su proyecto político contra los palestinos. Y, entre nosotros, algún cura vasco en alguna Iglesia había leído alguna vez un tex to de Isaías o de Oseas sobre el pueblo, para aplicarlo-sin referencia transparente a una clave de traducción- al actual pueblo vasco.

Todo esto lo planteo con una única intención metodológica. La de que es preciso introducir en el análisis de las teologías de la liberación también sus taíces inconscientes, $o$, al menos históricas, para que no sean tan fácilmente eludibles sus dimensiones analíticas. Esto no es, necesariamente, una crítica a esas teologías. Aunque sólo fuera porque toda teología es necesariamente histótica. Es simplemente la indicación del eventual exceso de hacer de ellas teologías dogmáticas, después de estar de vuelta de la teología dogmática como concepto mismo. Por eso comencé afirmando la posibilidad de crítica de ellas, incluso si esa crítica viene de Ratzinger o de Roma. Ante la crítica, no es de recibo negar su posibilidad sólo porque se oponga al proyecto acariciado. Lo único que es de recibo es desmontar su validez analítica

(2) Claude Villard, Le Socialisme de la Renaissence à nos jours, PUF. Paris, 1971 , pág. 50. 
o práctica, como crítica. Entonces, y sólo entonces, el debate tiene sentido. Para lo cual previamente es necesario negar, como cuadro del debate, el paradigma del Far West, donde los buenos - débiles- se oponen a los malos - fuertes- con la secreta convicción - inscrita en el género literario empleado- de que, a pesar de todo, los buenos se impondrán a los malos. Ya sé que la teología algo tiene que ver con lo de buenos y malos. Pero lo que está en debate ahora es el acierto o desacierto de una traducción teológica concreta, que presupone, sin excesivos análisis - más emocionalmente, en todo caso, que analíticamente- que unos son buenos y otros son malos. Este modo de hacer teología no es, sin más, ilícito. Como no lo es el modo de elección por consolaciones y desolaciones de los Ejercicios de Ignacio de Loyola. Pero analíticamente tiene in inconveniente, el de que su verdad histórica sólo se desvela cuando ya ha pasado el momento critico, el único en el que tiene algún interés práctico el análisis. Y en esta línea de análisis, las teologías de la liberación tiene - me parece- dos momentos débiles para la crítica. Uno, más propio de las teologías de la liberación europeas y otro, de las latinoamericanas. Analíticamente al menos a mí así me lo parece. Y ya digo que es esa perspectiva analítica la que, ahora y aquí, me interesa.

1.Vaya, ante todo, por delante que yo no veo dificultad alguna en el hecho mismo de una introducción de elementos marxianos en esa teología. La incompatibilidad entre marxismo y cristianismo que tradicionalmente ha jugado como elemento decisivo a la hora de este tipo de críticas - y que seguramente aletea por más de una frase del documento Ratzinger - no me parece hoy un elemento serio de crítica. Siempre naturalmente que haya una reelaboración de Marx, como la hubo de Aristóteles por parte de Tomás de Aquino. Pero eso es algo obvio. Marx pretendió ser todo, menos teología. Sin reelaboracion, pues, del pensamiento marxiano, no es posible por tanto hacer desde él una teología, sin provocar la hilaridad del Marx histótico, al que, como a todo clásico, se le debe respeto.

La corriente europea a la que ahora aludo ha hecho sin duda esa reelabotación, y la ha hecho en términos analíticos, no desprovistos además de finura y talento. Paul Blanquart (3) me parece un ejemplo expresivo de ella. Un viejo ejemplo, incluso algo arcaico ya en sus observaciones colaterales, pero un significativo ejemplo de esa reelaboración necesaria. Por eso to escojo ahora.

El análisis de Paul Blanquart lo que hace es sintetizar en dos o tres elementos la aportación, el mensaje... (podrían emplearse muchas expresiones distintas) de cristianismo y marxismo. El marxismo - piensa Blanquart - es tres cosas a la vez. 1) Primero y ante todo, una racionalidad operativa, capaz de explicar el funcionamiento de la sociedad real, de descubrir las causas de sus males, y de indicar líneas de acción para su remedio. 2) En segundo lugar, el marxismo es también una utopia, la del "hombre total" del joven Marx, la del "hombre integral" de Fidel Castro (aquí se nota demasiado el tiempo en que esto fue

(3) Christianisme et revolution (libro colectivo) Lettre, París, 1968, págs. 79-81. 
esctito). Y 3) finalmente, una ideología, y una ideología atea, claramente atea.

Por su parte el cristianismo es, para Blanquart: 1) Ante todo, una utopía, la del "hombre nuevo" del Nuevo Testamento. 2) También, una ideología y una ideología teocéntrica, claramente teocéntrica, en el sentido de que, en ese sistema de representaciones que para Blanquart es la ideología, Dios ocupa -y con qué importancia- el centro. 3) Finalmente, y contrariamente a lo que sucedía con el marxismo, el cristianismo no tiene ni puede tener - afirma Blanquart con absoluta razón- racionalidad alguna operativa que le sea propia. La utonomía de la razón afirmada por la teología lo impediría, y es imposible oponerse con lógica a ello.

Desde este panorama de materiales analíticos, es fácil ver los trazos esenciales de esa teología política que con Paul Blanquart (y con una buena parte del pensamiento teológico europeo) se diseña. Si se prescinde de los elementos ideológicos, por irrelevantes para el análisis (la racionalidad operativa) y para el horizonte del análisis (la utopía), la teología asumiría esa utopía cristiana (la del hombre nuevo como encarnación del Logos de Dios, en la fe cristiana, como utopía que es común, en cuanto horizonte no expresable en términos analíticos, a la utopía de expresión marxiana) y la trataría analíticamente - la desarrollaría en términos concretos- desde las categorías de la racionalidad operativa marxiana, que se convertiría así en utillaje teológico (teórico y práctico) para describir y entender historicamente el sitio y el cómo de la encarnación de la utopía-Logos de Dios. Como diseño lógico, es difícilmente discutible ese proyecto teológico.

Con una única reserva. Todo ese diseño implica, como un presupuesto lógico, implícito pero previo, que el único modo racional de pensar la realidad social son las categorías conceptuales puestas en circulación por el marxismo para entender la realidad social (la realidad encarnada en lenguaje cristiano, el topos de la utopía de la fe, en ese mismo lenguaje).

El debate entonces sobre la validez de ese tipo de teologías donde se sitúa es, no en la validez para la teología de un lenguaje nacido de un mundo no-teológico y hasta antiteológico (e incluso ateo), sino en la validez de ese lenguaje como expresivo de la realidad social, sobre la cual - y desde la cual - quiere expresarse el discurso teológico. Pero es más que discutible que el marxismo, como análisis o como instrumento de análisis, sea el único análisis posible, el único instrumento posible de análisis. Hay mucha gente, seria y sincera, que lo negaría, a partir de las ciencias sociales rigurosamente tomadas y de la experiencia de los hechos. Y, nos guste o no, ahí está el problema. La teología - o las teologías - de la liberación tienen que salirse del debate centrado sobre el discurso eclesiástico del "Roma sí -Roma no", "Iglesia jerárquica (opresora) - Iglesia de base (liberadora)", para debatir y cuestionat en un terreno preteológico - y no eclesiástico- los elementos analíticos que esas teologías presuponen, y donde se encierra la clave, el código úl timo de su validez teológica, como traducción humana del Logos de Dios. Porque si es difícil negar hoy que se pueda ser cristiano 
y ser marxista, más difícil me parece pretender hoy, a la altura de los años 80 del siglo $\mathrm{XX}$, y en términos analíticos, que para poder ser cristiano (verdadero cristiano) haya que ser marxista. $O$ que uno tenga que ver, por ello, reducida su fe, mal iluminada por la lógica de El Capital que no se escribió para eso, a la fe -emocional y adhesivadel carbonero.

2. Ese debate también es llevable al corazón de las teologías de liberación de signo latinoamericano. El drama de esas teologías, mucho más modestas que las europeas (en el sentido de menos orgullosas), con menos pretensiones de universalidad que las europeas (por más modestas y porque han nacido más cerca de la historia teal de miseria y explotación de grandes zonas de "sus" pueblos) es que, también están, a pesar de todo, sometidas a esa misma pregunta, previa y directamente analítica, de las ciencias sociales modernas, sobre qué es lo que causa esa miseria y dónde están las soluciones políticas, económicas y sociales a esos problemas de miseria. Suponer que la clave está en el análisis marxista, puede servir para darse una buena conciencia heroica (bien antimarxista, por cierto), pero no sirve necesatiamente para encontrar el camino de solución de esos problemas, que están ahí, interrogando más a las ciencias sociales que a la teología, y a los que la teología tiene su propia respuesta que dar, pero sin poder eludir las previas respuestas de aquéllas.

En esto, las teologías de la liberación de signo la tinoameticano tienen que enfrentarse con el mismo reto que las de signo europeo. Pero su debilidad mayor no radica en esto. Su mayor modestia teológica, su menor pretensión de universalidad cultural, incluso su mayor cercanía a un pueblo concreto en el que es demasiado fácil ver la opresión recurrente, les dispensaría, con más facilidad que a los europeos, de un trabajo analítico previo, en el que no parecen hacerse fuertes estas teologías, más preocupados de la pura predicación de la Explosión concreta y encarnada del Logos Redentor de Dios en un mundo sin esperanza visible.

Pero ahí me parece que radica su otro teto más propio suyo, y al que no sé si esas teologías responden con la precisión y el rigor que el empeño analítico de toda teología exigiría. El de no hacer coincidit (sin todos los distingos y contradistingos de la vieja Escolástica) la esperanza invisible de Dios con la esperanza visible que el marxismo predica, Yo comprendo que Marx - más utópico que científico, a pesar suyo, en más de una afirmación básica suya- se presta a ello. Como también comprendo que, a partir de la tesis concocida de Schumpeter - del Marx más profeta que economista o sociólogouna cierta teología se sienta llamada a identificar - sin quererlo - la profecía de Marx con la profecía cristiana. La llamada profética se hace así más atractiva, más moderna y más concreta. Lo que no sé es si se hace más profética, en el sentido cristiano del término, no sólo en el étnico-simbólico, al que Marx, judío a fin de cuentas (a pesar de su Zur judischen Frage), era culturalmente sensible.

De hecho es posible establecer una cierta lectura paralela entre Marx (Contribución a la Crítica de la Filosofía hegeliana del Derecho, 
la Ideología Alemana y el mismo Manifiesto) y el Deutero-Isaías (Is, 52-53). Dos lecturas paralelas montadas ambas, sobre la paradoja - isemita o dialéctica? - de la salvación radical a partir de la disolución y la pérdida radicales.

"¿Dónde existe - se pregunta Marx- una posibilidad real de emancipación?" Y contesta. "En la formación de una clase con cadenas radicales, una clase de la sociedad civil que no sea una clase de la sociedad civil (...), que no reivindique un derecho particular porque no se ha hecho una injusticia particular, sino la injusticia puta y absolutamente, una esfera de la sociedad que ya no pueda invocar un título histórico, sino sólo el título humano (...), una esfera, en fin, que no pueda emanciparse a sí misma sin emanciparse de todas las otras esferas de la sociedad, $y$, por ello mismo, sin emancipar al tiempo a todas las otras esferas de la sociedad; una esfera, que sea, en una palabra, la pérdida total de la humanidad. Esta disolución - concluye Marx- de la sociedad en cuanto clase particular es el proletariado ("Contribución a la Crítica...", los subrayados son de Marx). Una conclusión redentora que se confirma en La Ideología Alemana, donde esa redención total (descrita triunfalmente en El Manifiesto) sólo es posible "en la realidad, por una clase que en la sociedad ya no es valorada como clase ni reconocida como clase, sino que es ya la expresión, en el interior de la actual sociedad, de la disolución de todas las clases", el proletariado. (Aquí los subrayados son míos.)

Comparénse estos textos de Marx (releídos, como ya he sugerido, desde la apoteosis de el Manifiesto) con la lectura del Deutero-Isaias a que toe he referido, y se verá la dificultad psicologica de ciertas teologías de hoy, nacidas al calor de la vida y la experiencia del dolor y la opresión, para oponerse a la atractiva tentación de ver en el proletariado marxiano (marxiano en su fuerza redentora, no necesariamente marxiano en su descripción económico-sociológica) al Varón de dolores de Deutero-Isaías.

"Mirad - dice el Deutero-Isaías- mi siervo tendrá éxito, subirá y crecerá mucho/como muchos se espantaron de él/porque desfigurado no parecía hombre/ni tenía aspecto humano;/así asombrará a muchos pueblos; ante él los reyes cerrarán la boca,/al ver algo inenarrable y contemplar algo inaudito" (...) Lo vimos sin aspecto atrayente,/despreciado y evitado de los hombres,/como un hombre de dolores acostumbrado a sufrimientos (...) traspasado por nuestras rebeliones/triturado por nuestros crímenes./ Nuestro castigo saludable cayó sobre él,/sus cicatrices nos curaton. (...) Verá su descendencia/prolongará sus años,/ lo que el Señor quiere prosperará por su mano. (...) Mi siervo justificará a muchos/porque cargó con los crímenes de ellos". (No hace falta decir, claro está, que los subrayados, que sólo pueden ser míos, pretenden ayudar a la lectura paralela que propongo.)

En efecto, los rasgos comunes de esa lectura paralela son tres: 1) Salvación futura del proletariado/varón de dolores hundidos. 2) Salvación redentora, con ellos, de todos (de todas las clases, de los "muchos" bíblicos). 3) Salvación a través de un proceso de hundi- 


\section{ANTONIO MARZAL}

miento radical, que es más que histórico-concreto, que es un proceso simple y absolutamente humano, totalizante de la historia, de algún modo esencial.

Ahora bien, más allá de esas semejanzas formales icoinciden los dos procesos de redención, el bíblico y el marxiano? Es posible dudar de ello. Como también es posible afirmar que no es necesaria su radical coincidencia. Pero en todo caso, una teología que utilice la coincidencia, debería explicar analíticamente el cómo y el por qué de ella, - si afirma o parte de esa coincidencia-. Para lo cual, no puede contentarse sólo con la emoción primariamente romántica de la experiencia humana del dolor (inaceptable, es cierto, como dato último para un hombre de fe), sino que tiene que interrogarse, en términos analíticos, que no pueden obviar los datos de las modernas ciencias sociales y la de la hermenéntica bública más estricta, sobre las posibilidades de identificación del concepto de pueblo (el concepto bíblico y también el concepto sociológico de las ciencias sociales de hoy) con el concepto económico del proletariado marxiano (concepto que, en términos estrictamente marxianos, no es, sin más, el concepto de pueblo). El tema no es, como ya sugetí antes, el de la compatibilidad de marxismo y cristianismo (tema que hoy me parece que está claro) sino el de la posibilidad de hacer del proletariado marxiano $-y$, en contra, quizás, de la intención de Marx- un concepto teológico y un concepto teológico analíticamente preciso. La mera "opción por los pobres", siendo cristianamente necesaria, es insuficiente para esto. Un deslizamiento no pretendido (pero tampoco suficientemente contrastado con los hechos) en este campo semántico, podría hacer de una historia teológica, una simple película del Far West. Algo que no creo que entre en la intención de ninguna teología.

\section{Conclusión}

Y concluyo con ello. La alusión que acabo de hacer al Far West no tiene intención alguna descalifica toria. Probablemente, las teologías de la liberación son, en el panorama de las teologías modernas, unas de las mejores expresiones religiosas - en cuanto testimonio y vivencia-de la historia humana como historia salvada. Pero ese modo religioso de plantearlo así sólo es un planteamiento parcial, en la medida en que rehúye su necesario planteamiento analítico. Mucho más lo es aún, cuando el planteamiento se reduce - como con demasiada frecuencia sucede - a un problema de teologías progresistas contra teologías conservadoras, o a un problema de teologías de base contra teologías romanas (como, el caso Ratzinger - y su contestación-está facilitando, sin quererlo). El problema, a mi juicio, está en el mismo término (si no equívoco, sí, al menos, polisémico) de liberación. La liberación de Dios, como objeto teológico, exige, previamente, la discusión analítica del propio término "liberación". Está en juego, entre otras cosas, la propia autonomía de la ciencia y la razón, que ha sido una conquista definitiva de toda teología moderna. 